\title{
In memoriam: a tribute to Teruo Omae, MD PhD
}

\author{
Koshiro Fukiyama $^{1} \cdot$ Tanenao Eto $^{1} \cdot$ Shuichi Takishita ${ }^{1} \cdot$ Yuhei Kawano $^{1} \cdot$ Takuya Tsuchihashi $^{1} \cdot$ Yusuke Ohya $^{1}$
}

Received: 14 July 2021 / Accepted: 14 July 2021 / Published online: 15 September 2021

(c) The Japanese Society of Hypertension 2021

Dr Teruo Omae, our much-admired teacher and leader (mentor), died from a stroke and subsequent complications after a long history of end-stage renal disease. We, six former and present board members of the Japanese Society of Hypertension, will have lasting memories of him and want to let the world know how he contributed to the progress of the research, practice, and policies of hypertension control and the prevention of cardiovascular diseases. He graduated from Japan's Naval Academy as one of the most-honored representatives in October 1945. He then entered Kyushu University School of Medicine in 1946. After graduation, he joined the Second Department of Internal Medicine and started his career as a researcher and a clinician of internal medicine. After leading impactful research on not only hypertension but also kidney disease, he then extended his career by joining Dr. Page's laboratory at Cleveland Clinic, USA, the world center of hypertension research. Dr Teruo Omae spearheaded several important works on renin, renal disease related to salt-dependent hypertension, and other conditions at Cleveland Clinic. There, he also created a great network and developed many friendships among researchers from all over the world, including Japanese fellows Dr Arakawa from Kyushu University, Dr Kaneko from the University of Tokyo, and others who worked together to establish The Japanese Society of Hypertension in later years.

He returned to Kyushu University in 1961 and extended his research in the field of cardiology, kidney diseases, and stroke. In 1971, Dr Omae became a professor and chairman of the Second Department of Internal Medicine at Kyushu University. Although he accumulated many achievements during his 12-year history of professorship at Kyushu University, we will mention only two of them here. One is the substantial promotion and development of the

Yusuke Ohya

ohya@med.u-ryukyu.ac.jp

1 Hypertension Researchhttps://www.nature.com/hr/ sustainable system of the Hisayama study. The Hisayama study, established in 1961 and continuing to this day, has become one of the most important prospective cohort studies in the world. More than 400 original articles have been published from the Hisayama study. The second achievement is the establishment of The Japanese Society of Hypertension. With a considerable influence from the activities of Cleveland Clinic and the Council for High Blood Pressure Research, Drs Omae, Arakawa, and Kaneko; several alumni of the Cleveland Clinic; and others made a great effort to establish the Japanese Society of Hypertension. Due to their enthusiastic efforts, The Japanese Society of Hypertension was established in April 1978 with $\sim 300$ members. This society has led research on basic, clinical, and public aspects of hypertension in Japan and has extended these activities to other areas, including Asian countries.

In 1983, Dr Omae moved to the National Cardiovascular Center (currently the National Cerebral and Cardiovascular Center) in Osaka, Japan, as a director and later became a president in 1990. He turned the National Cardiovascular Center into one of the world's leading cardiovascular centers. During his tenure at the National Cardiovascular Center, Dr Omae organized and conducted many international meetings in the field of hypertension, stroke, and cardiovascular diseases, including The Scientific Meeting of the International Society of Hypertension, The International Conference on Preventive Cardiology, The JapaneseAustralian Collaborative Cardiovascular Research Forum, The China-Japan Symposium on Cardiovascular Diseases, International Stroke Society, Asia Pacific Stroke Conference, and The US-Japan Symposium under the collaboration of National Cardiovascular Center and National Heart, Lung, and Blood Institute. He received Grand Cordon of the Order of the Sacred Treasure in 1999 due to his long-term contribution to public health, disease control, and advances in science and technology.

Another great achievement by Dr. Omae is that he trained many young researchers at Kyushu University and the National Cerebral and Cardiovascular Center. Our six 
members, who now write this memorial, are some of those researchers. He treated young researchers as his sons and daughters. We know that his wife, Nobuko, contributed greatly to this dynamic. For example, many young researchers, including us, have great memories of delightful parties in his home. Some of them also had a great time with him mountain climbing. Mrs Omae, his lifelong partner, died in 2019. Dr Omae suffered a stroke and passed away, joining his lovely wife. We would like to express our gratitude and mourn the loss of Dr Omae, a great teacher and mentor. We hope that he enjoys a lovely and peaceful afterlife with his wife.

Dr and Mrs Omae, when Dr Omae was 91 years old (May 18, 2018)

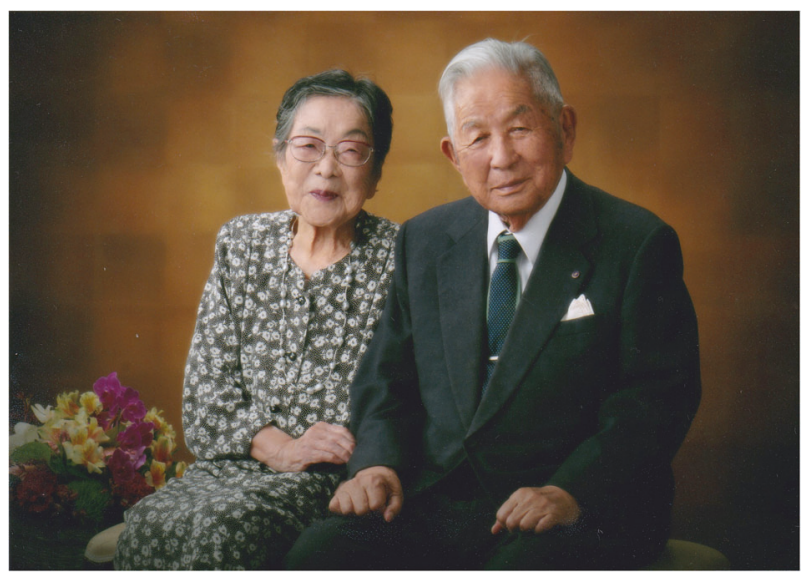

Publisher's note Springer Nature remains neutral with regard to jurisdictional claims in published maps and institutional affiliations. 